Lynne Bowker, (2017) "Aligning accreditation and academic program reviews: a Canadian case study", Quality Assurance in Education, Vol. 25 Issue: 3, pp.287-

302, https://doi.org/10.1108/QAE-11-2016-0061

\title{
Aligning accreditation and academic program reviews: A Canadian case study
}

Lynne Bowker, University of Ottawa

\begin{abstract}
Purpose - This policy paper investigates the potential benefits and limitations associated with aligning accreditation and academic program reviews in post-secondary institutions, using a descriptive case study approach.

Design/methodology/approach - The paper describes two Canadian graduate programs that are subject to both external professional accreditation and institutional cyclical reviews, as they underwent an aligned review. The process was developed as a collaborative effort between the academic units, the professional associations, and the university's graduate-level quality assurance office. For each program, a single self-study was developed, a single review panel was constituted, and a single site visit was conducted. The merits and challenges posed by the alignment process are discussed.

Findings - Initial feedback from the academic units suggests that the alignment of accreditation and program reviews is perceived as reducing the burden on programs with regard to the time and effort invested by faculty, staff, and other stakeholders, as well as in terms of financial expenses. Based on this feedback, along with input from reviewers and program evaluation committee members, fourteen recommendations emerged for ways in which an aligned review process can be set up for success.

Practical implications - The results suggest that not only are aligned reviews resource-efficient, but they also allow reviewers to provide more holistic feedback that faculty may be more willing to engage with for program enhancement.
\end{abstract}

Originality/value - The present study contributes to the existing body of knowledge about conducting aligned reviews in response to external accreditation requirements or institutional needs. It summarizes the potential benefits and limitations and offers recommendations for potential best practices for carrying out aligned reviews for policymakers and practitioners. Keywords Academic program review, Cyclical review, Professional accreditation, Alignment of reviews, Resource-efficient assessment, Institutional quality assurance process Paper type Policy Article 


\section{Introduction}

Countries around the world, including Canada, have recognized the importance of quality assurance (QA) in post-secondary education and have implemented processes for academic program review (e.g. Tam, 1999; Brown, 2004; Mora, 2004; Shah et al., 2007; Weinrib and Jones, 2014). Essentially, quality assurance involves implementing a series of ongoing processes and policies that are intended to maintain and continuously improve academic program standards. Quality assurance processes in higher education institutions include assessing, monitoring, guaranteeing, maintaining and improving system-wide processes and outcomes (Vlăsceanu et al., 2007: 74). In Canada, the quality assurance system is multi-layered, and the roles are shared among provincial and/or regional authorities and the post-secondary institutions themselves.

Additionally, in Canada, external accreditation is the process by which university programs in professional fields (e.g. physiotherapy, library science) are subjected to external review and accreditation by professional bodies at the relevant provincial, national or international levels. Accreditation by professional bodies ensures that the content of university programs, teaching resources, and research outputs are of consistently high quality to meet competency expectations and to support future professionals in their area of expertise. As a process, accreditation is used to evaluate whether a program meets certain pre-determined minimal criteria or standards set by external bodies (Vlăsceanu et al., 2007: 25). One common procedural characteristic of both accreditation and academic program reviews is the development of a self-study process by the program undergoing review.

According to the Macmillan English Dictionary, alignment means "the organization of activities or systems so that they match or fit well together." There is a burgeoning interest in learning more about the potential benefits and limitations of aligning the processes involved in academic program reviews with those involved in professional accreditation reviews (e.g. Guitard and Savard, 2016: 5; Materu, 2007: 53). Post-secondary institutions devote considerable time and resources towards assessing and reporting on the quality of their programs and in fulfilling the requirements set out by provincial authorities and accreditation bodies. Both types of review processes can be rigorous and demanding, and they require a considerable investment on the part of an academic unit.

Programs are typically reviewed on a cycle that ranges between five and ten years, and formal preparation for each review could span several years. Given that the vast majority of academic units offer multiple programs, some of which may require both institutional and professional accreditation reviews, it is not unusual for these units to be in a near constant state of preparing for a program review or fulfilling a reporting requirement. There are numerous accounts in the literature suggesting that faculty and staff members often view these preparations and reporting processes as labour-intensive and time-consuming (e.g. Jones and Darshi de Saram, 2005: 52; Strydom et al., 2004: 213; Cardoso et al., 2016: 952).

Given this contingency, Subramony et al. (2015) were recently motivated to explore the possibility of aligning program reviews and national/state accreditation reviews at Northern Illinois University in the United States. In their paper entitled "Towards an aligned accreditation and program review process: Institutional case study," Subramony et al. (2015) outline their efforts to collaborate with different programs and administrative units to develop prototypes of aligned standards with a view towards creating a resource-efficient assessment system. 
Meanwhile, there is evidence of a growing interest in finding ways to maximize efficiency in the program review process in Canada as well. For instance, the topic of aligning accreditation and program reviews was on the agenda for the 2016 "Quality Assurance Key Contacts Meeting". This meeting, which is organized annually by the Ontario Universities Council on Quality Assurance (OUCQA), targets faculty and staff who are responsible for managing the quality assurance processes in the 23 publicly assisted universities in the province of Ontario, Canada. At the 2016 meeting, the program included a two-hour interactive session entitled "Making Quality Assurance Work." During the session, five specific QA-related challenges were raised, and participants were asked to weigh in with questions, comments, suggestions, or experiences. One of the five challenges to be addressed was "Alignment of accreditation and Institutional Quality Assurance Process program reviews."

To start the session, the moderator stated that aligning academic program reviews and accreditation reviews can be challenging, noting that only one of the 23 Ontario universities had formally provided for this approach in their the institutional quality assurance process. The discussion was lively, but it consisted of more questions than answers. Anecdotally, many participants reported that they were regularly approached by faculty and staff at their home institutions who asked whether different types of reviews could be combined to try to reduce the volume of work associated with the review process. However, none of the participants at the meeting had successfully completed an aligned review at that time.

\section{Case Description: A Canadian Institutional Review}

\section{Institutional context of case}

Like our colleagues at other universities in Ontario and beyond, the quality assurance team at the University of Ottawa's Faculty of Graduate and Postdoctoral Studies has been approached on multiple occasions by academic units enquiring about the possibility of aligning different types of program reviews. In an effort to gain a deeper understanding, and to contribute to a wider discussion about the potential benefits and limitations of aligning professional accreditation and academic program reviews, the graduate quality assurance team undertook a one-year pilot project. As part of this pilot, two different graduate programs, delivered by two different Faculties, participated in aligned reviews: the Master of Health Science in Occupational Therapy, and the Master's and PhD degree programs in Social Work.

In the following section, the regulatory context for quality assurance at the University of Ottawa is presented. Next the two programs that were part of the pilot project are introduced, and the process that was followed to align the institutional academic program review with each of the relevant professional accreditation reviews is outlined. The results of the pilot project are discussed and, based on this experience and the lessons learned during the project, we present a number of recommendations that could be useful for carrying out future aligned reviews. Finally, we conclude with a summary of some of the potential benefits and limitations of aligned reviews.

\section{Regulatory Context: Quality assurance in Ontario and at the University of Ottawa}

In Canada, public education falls under the mandate of the provincial and territorial governments. The University of Ottawa is situated in the province of Ontario, where universitylevel quality assurance processes have grown in importance over the past 50 years. Goff (2013) and Liu (2015) provide detailed descriptions of the history of university quality assurance in Ontario, so only a brief summary of the key points is provided here. 
In 1968, external appraisals of new graduate programs became a requirement, and by 1982, graduate programs began undergoing periodic external appraisals through the Ontario Council on Graduate Studies (OCGS). This process operated largely unchanged until 2007, when the Executive Heads of Ontario Universities commissioned a review of the OCGS's appraisal processes and operations. As a result of this review, the Ontario Universities Council on Quality Assurance (OUCQA) was formed, and by 2010, a Quality Assurance Framework was introduced and adopted by all publicly assisted universities in Ontario. The OUCQA, which is responsible for the oversight of the QAF processes for Ontario universities, operates at arm's length from both Ontario's publicly assisted universities and the provincial government.

Each university has developed its own Institutional Quality Assurance Process (IQAP), which is subject to review and approval by the OUCQA. The requirements for the IQAP are set out in the QAF, and each university's quality assurance processes are audited regularly by the OUCQA. One of the components that must be incorporated into a university's IQAP is a protocol for the cyclical review of existing programs at least once every eight years to secure academic standards and ensure ongoing improvement.

At the University of Ottawa, undergraduate and graduate cyclical reviews are managed by different offices and they follow slightly different processes, as outlined in the IQAP. This paper focuses only on graduate program reviews, which are managed by the Faculty of Graduate and Postdoctoral Studies, and more specifically, by a team comprising the Vice-Dean, the Director of Quality Assurance, and the Quality Assurance Coordinator. The Graduate Program Evaluation Committee (GPEC) also plays a key role. The GPEC is chaired by the Vice-Dean and its members include one professor from each of the nine disciplinary faculties (Arts, Education, Engineering, Health Sciences, Law, Management, Medicine, Science, and Social Sciences), as well as a professor from Saint Paul University (which is federated with the University of Ottawa), and several resource personnel, such as the abovementioned Director and Coordinator of QA, as well as a graduate curriculum development specialist from the Centre for University Teaching.

\section{Quality Assurance Review Process}

The process for the cyclical review of existing programs begins with the development of a detailed self-study prepared by the academic unit delivering the program, following a template designed by the QA office in accordance with the QAF requirements. The self-study provides a comprehensive presentation of the program's objectives, learning outcomes, curriculum, admission criteria, faculty members, student body, governance and administration, and resources and services, among other information. Once completed, a typical self-study is approximately 80 to 100 pages in length, often with additional appendices. The self-study is then sent to three reviewers who have been selected by the GPEC (at least two of whom must be external to the university).

The reviewers later come to the campus for a site visit where they meet with the various program stakeholders. Following the site visit, the reviewers submit a report in which they identify the strengths and weaknesses of the program and also make recommendations for its enhancement. The academic unit has an opportunity to respond to the reviewers' report. Finally, these three key documents - the self-study, the reviewers' report and the unit's response - are considered by the GPEC, which makes a determination with regard to a program's quality, identifies any necessary improvements, and reports the results back to the OUCQA. The 
university's graduate QA office is responsible for monitoring the implementation of any recommendations.

\section{Policies on Alignment of Accreditation and Program Reviews}

With regard to the potential alignment of accreditation and academic program reviews, the OUCQA notes on its website that the QAF (section 4.2.7) does allow for such a possibility, and it goes on to make the following observation: "Combining cyclical program review and accreditation reviews can be challenging given the different purposes and evaluation criteria that apply. [...] As universities gain experience with periodic reviews guided by their IQAP, it is anticipated that more examples of best practice with respect to the cyclical review of accredited programs will be forthcoming."

Meanwhile, the University of Ottawa's IQAP (section 6.2.1.1) also allows for the possibility of aligning a professional accreditation review with a cyclical program review, but it provides only limited guidance in this respect:

In the case of programs that undergo professional accreditation, the Graduate Program Evaluation Committee, in consultation with the Dean of the Faculty of Graduate and Postdoctoral Studies, will decide upon the manner in which elements from the accreditation process (where possible and appropriate) may be integrated into the cyclical review process, all the while ensuring that the exigencies and policies of the evaluation process are respected.

\section{A Pilot Study}

In this context, the University of Ottawa's Graduate Program Evaluation Committee elected to undertake a pilot project to gather more information about the potential benefits and limitations of aligning professional accreditation reviews and academic program reviews in the hopes of contributing to the somewhat limited body of knowledge about aligned reviews. Table I provides a comparative summary of the main purpose and process associated with an IQAP review and professional accreditation reviews for programs in Occupational Therapy and Social Work.

\begin{tabular}{|c|c|c|c|}
\hline & $\begin{array}{l}\text { Academic program review } \\
\text { through the Institutional } \\
\text { Quality Assurance Process } \\
\text { (IQAP) }\end{array}$ & $\begin{array}{l}\text { Accreditation by the Canadian } \\
\text { Association of Occupational } \\
\text { Therapists (CAOT) }\end{array}$ & $\begin{array}{l}\text { Accreditation by the Canadian } \\
\text { Association for Social Work } \\
\text { Education (CASWE) }\end{array}$ \\
\hline Purpose & $\begin{array}{l}\text { - to help each program to } \\
\text { achieve and maintain the } \\
\text { highest possible standards } \\
\text { of academic excellence, } \\
\text { through systematically } \\
\text { reflecting on its strengths } \\
\text { and weaknesses, and } \\
\text { looking forward to } \\
\text { determine what actions } \\
\text { would further enhance } \\
\text { quality in the program; } \\
\text { - to assess the quality of the } \\
\text { program relative to } \\
\text { counterpart programs in }\end{array}$ & $\begin{array}{l}\text { - to maintain consistent } \\
\text { national standards; } \\
\text { - to ensure quality } \\
\text { professional education; } \\
\text { - to support the growth and } \\
\text { development of educational } \\
\text { programs and the } \\
\text { occupational therapy } \\
\text { profession; } \\
\text { - to monitor educational } \\
\text { standards worldwide so as } \\
\text { to assess trends and ensure } \\
\text { better graduate mobility. }\end{array}$ & $\begin{array}{l}\text { - to ensure excellence in } \\
\text { social work education and } \\
\text { continuing quality } \\
\text { improvement in social work } \\
\text { curriculum and pedagogy } \\
\text { across Canada; } \\
\text { - to ensure the relevance of } \\
\text { social work education } \\
\text { programs to professional } \\
\text { practice. }\end{array}$ \\
\hline
\end{tabular}




\begin{tabular}{|c|c|c|c|}
\hline & $\begin{array}{l}\text { Ontario, Canada and } \\
\text { internationally; } \\
\text { - to meet public } \\
\text { accountability expectations } \\
\text { through a credible, } \\
\text { transparent, and action- } \\
\text { oriented review process; } \\
\text { - to create an institutional } \\
\text { culture which understands } \\
\text { and values the benefits of } \\
\text { program reviews, while } \\
\text { recognizing the significant } \\
\text { workload implications of } \\
\text { preparing a self-study, } \\
\text { hosting a site visit, and } \\
\text { providing progress reports. }\end{array}$ & & \\
\hline Process & $\begin{array}{l}\text { a) Self-study developed by } \\
\text { program; } \\
\text { b) Review of self-study by } \\
\text { external and internal } \\
\text { reviewers (peer review); } \\
\text { c) Site visit by reviewers with } \\
\text { report and recommendations } \\
\text { on program quality } \\
\text { improvement; } \\
\text { d) Response from the } \\
\text { program; } \\
\text { e) Institutional evaluation of } \\
\text { the self-study, the reviewer } \\
\text { report and program response } \\
\text { resulting in } \\
\text { recommendations for } \\
\text { program quality } \\
\text { improvement; } \\
\text { f) Decision-making by the } \\
\text { Graduate Program } \\
\text { Evaluation Committee; } \\
\text { g) Follow-up reporting on the } \\
\text { principal findings of the } \\
\text { review and the } \\
\text { implementation of the } \\
\text { recommendations. }\end{array}$ & $\begin{array}{l}\text { a) Self-study developed by } \\
\text { program; } \\
\text { b) Review of self-study by } \\
\text { external reviewers; } \\
\text { c) Site visit by external } \\
\text { reviewers; } \\
\text { d) Report identifying } \\
\text { strengths and areas for } \\
\text { improvement that are } \\
\text { documented by external } \\
\text { reviewers in a Continuous } \\
\text { Quality Improvement (CQI) } \\
\text { plan; } \\
\text { e) Decision making by } \\
\text { CAOT's Academic } \\
\text { Credentialing Council } \\
\text { (ACC); } \\
\text { f) Possible follow-up } \\
\text { reporting before next } \\
\text { review. }\end{array}$ & $\begin{array}{l}\text { a) Self-study developed by } \\
\text { program; } \\
\text { b) Review of self-study by } \\
\text { external reviewers; } \\
\text { c) Site visit by external } \\
\text { reviewers; } \\
\text { d) Review of Site Visit } \\
\text { Reports (by the CASWE } \\
\text { Commission on } \\
\text { Accreditation (COA)); } \\
\text { e) Decision making (by the } \\
\text { COA). } \\
\text { f) Possible follow-up reporting } \\
\text { before next review. }\end{array}$ \\
\hline $\begin{array}{l}\text { Review } \\
\text { cycle }\end{array}$ & At least once every 8 years. & At least once every 7 years. & At least once every 8 years. \\
\hline
\end{tabular}

Table I. Comparative summary of the main purpose and process associated with institutional program reviews (IQAP) and professional accreditation reviews (CAOT and CASWE).

The pilot project took place over a 12-month period, between October 2015 and October 2016. During this time, two graduate programs - Occupational Therapy and Social Workparticipated in an aligned review process that allowed them to align their cyclical program review with a professional accreditation review. Both programs followed a collaborative review process that included four main steps: 1) review and gap analysis of guidelines and expectations 
for the two review types to determine an appropriate format for the self-study and $\operatorname{report}(\mathrm{s}) ; 2)$ selection of reviewers; 3) site-visit; and 4) follow-up/feedback discussions.

\section{Occupational Therapy}

The first program to participate in the pilot study was the Master of Health Science in Occupational Therapy, which is delivered by the School of Rehabilitation Sciences in the Faculty of Health Sciences. This aligned review was carried out in collaboration with the Canadian Association of Occupational Therapists (CAOT), which is Canada's recognized professional accrediting body in this field.

The academic unit approached the Graduate Program Evaluation Committee (GPEC) with a request to prepare a single self-study and to coordinate the site visit. As a first step, the GPEC asked to see the guidelines and expectations for the self-study preparation. These were provided in the form of the CAOT Academic Accreditation Standards and Self-Study Guide. This document was examined by the GPEC members, who observed that it set out thorough and rigorous expectations. By coincidence, a professor from the Occupational Therapy program was the representative for the Faculty of Health Sciences on the GPEC. This was extremely helpful because this professor was able to thoroughly explain the expectations of the accrediting body, as well as their accreditation process, and to answer questions posed by GPEC members. Although she abstained from all votes on this issue (and withdrew during voting), her participation in the discussions was instrumental in helping the other GPEC members to gain a deeper understanding of the issues surrounding accreditation and how they related to cyclical program review.

Following these discussions, which took place over multiple meetings, the GPEC members agreed that the unit could submit the self-study prepared according to the CAOT standards and guidelines for their consideration; however, they reserved the right to request supplementary information if necessary. Following the submission of the self-study, the GPEC conducted a gap analysis which consisted of comparing the list of reporting requirements for a cyclical program review against the self-study document that had been prepared to address the CAOT standards. Following this analysis, the GPEC members concluded that although the material in the self-study was organized differently, it nonetheless contained all the essential elements that would normally be found in a self-study prepared using the template for cyclical reviews. The GPEC therefore voted to accept the self-study with no modifications.

Next, the question of reviewer selection was addressed. The CAOT had already nominated an external review team, which consisted of one senior professor (who was also a program administrator), one practitioner who was a licensed occupational therapist with a master's degree, and one member of the public who was neither an academic nor an occupational therapist, but who did have prior experience with accreditation reviews. For a cyclical review, the University of Ottawa's IQAP requires that there be three reviewers, at least two of whom must be external. In accordance with the guidelines provided by the QAF, the reviewers should typically have a strong track record as a scholar, as well as experience as an academic administrator. In reviewing the profiles of the candidates nominated by the CAOT, the GPEC members felt that it would be appropriate to add a fourth reviewer who was also an experienced scholar and academic administrator. The IQAP allows for one member of the review panel to be internal to the University of Ottawa, but insists that such a reviewer must come from another Faculty and be free of any conflict of interest with the program. The GPEC therefore nominated a professor from the University of Ottawa's Telfer School of Management who holds a research chair in workplace psychology and has experience as the director of the doctoral program in 
management. The CAOT was consulted and they agreed to the addition of this fourth reviewer to the review panel.

With regard to the reports to be produced by the reviewers, the GPEC and the CAOT agreed on the following process. The three reviewers nominated by the CAOT would prepare a report that would be submitted directly to the CAOT and which would then be shared in full with the GPEC. Meanwhile, the fourth reviewer, who was nominated by the GPEC, would prepare an independent report that would be submitted directly to the GPEC and would then be shared in full with the CAOT. It was recommended that, while the reviewers would produce independent reports, they could collaborate and seek to minimize overlap in content on the understanding that both reports would be read "together" and could therefore provide a fuller picture where different perspectives were represented.

The site visit took place between February 8 and 10, 2016. All four members of the review team met with the various program stakeholders. The final meeting was a wrap up session where both the CAOT reviewers and the University of Ottawa reviewer presented a high-level overview of their findings and recommendations. The two official reports were submitted several weeks later.

As indicated above, the GPEC considered both of the reviewers' reports as part of their overall deliberations and assessment. Using information from these reports, as well as from the original self-study and the unit's response, the GPEC members prepared a Final Assessment Report, with input and support from the academic unit responsible for the program.

A follow-up discussion was held with two of the reviewers - one nominated by the CAOT and one nominated by the GPEC - about one month after the site visit and after both reports had already been submitted. The goal was to get feedback from the reviewers about the aligned review process. Similarly, the program coordinator was also asked to provide feedback on behalf of the academic unit about this process. Both the reviewers and the program coordinator shared some suggestions, and these will be discussed in an upcoming section as part of the overall evaluation of this pilot project.

To sum up, the steps followed to align the academic program and accreditation reviews for the Occupational Therapy program were as follows:

- guidelines and expectations for external accreditation studied by the GPEC;

- $\quad$ self-study prepared by the program according to external accreditation guidelines;

- gap analysis conducted by the GPEC, who request supplementary information if necessary;

- review panel selected with some members being nominated by the external accreditation board and others by the GPEC;

- $\quad$ site visit conducted by combined review panel;

- independent but coordinated reports produced by the two sets of reviewers;

- decisions made independently by the GPEC (for academic program review) and the external accreditation board (for the accreditation review).

\section{Social Work}

The second group to participate in the pilot study was the School of Social Work in the Faculty of Social Sciences. In this case, two programs - the Master's in Social Work and the PhD in Social Work-were due to undergo a cyclical review. However, only the Master's degree program was being reviewed by the accrediting body, which is the Canadian Association for Social Work Education (CASWE). 
Once again, the GPEC began by asking to see the standards and guidelines set forth by the professional association for producing a self-study, and once again, it was agreed that an initial version of the self-study could be prepared using these guidelines. Following a gap analysis of this initial draft, the GPEC requested that supplementary material be provided, particularly with regard to the doctoral program as this program was not being reviewed as part of the accreditation review. Following a discussion with CASWE, it was agreed that the material pertaining to the doctorate could be incorporated into the original self-study, to produce a single hybrid document, rather than having two separate documents. It was agreed that this approach would provide a more coherent overview for the reviewers, and that even though the doctoral program was not subject to professional accreditation, a holistic presentation of the School's graduate offering would provide an informative context for all the reviewers.

With regard to the reviewer selection, the CASWE nominated two reviewers, both of whom are experienced scholars and academic administrators. Because the IQAP requires at least three evaluators to participate in a cyclical review, and because the cyclical review needed to address the doctoral program as well as the master's, the GPEC nominated an additional two reviewers, who are also respected scholars and administrators. The CASWE agreed to the participation of the two additional reviewers, and it was also agreed that while one of the CASWE reviewers would focus exclusively on the accreditation review, the second one would also contribute to the cyclical review.

As was the case for the Occupational Therapy program, it was decided that two separate reports would be produced. The reviewers nominated by the CASWE would prepare a report that would be submitted directly to the CASWE and which would then be shared in full with the GPEC. Meanwhile, the reviewers nominated by the GPEC would prepare a separate report that would be submitted directly to the GPEC and would then be shared in full with the CASWE. Once again, it was recommended that, while the two sets of reviewers would produce independent reports, they could collaborate and seek to minimize overlap in content given that both reports would be read "together" to obtain a fuller picture.

The site visit took place between October 12 and 14, 2016, during which time the members of the review team met with the various stakeholders of both the master's and doctoral programs. The final meeting was a wrap up session where all the reviewers presented a highlevel overview of their findings and recommendations, with the official reports to follow.

At the end of the wrap-up session, the reviewers also shared their feedback about the aligned review process, including some suggestions for improvement. The academic unit also provided feedback on the experience. These and other recommendations are presented in the following section.

As compared to the first program, the steps followed by the Social Work program were generally similar. They were:

- guidelines and expectations for external accreditation studied by the GPEC;

- $\quad$ self-study prepared by the program according to external accreditation guidelines;

- gap analysis conducted by the GPEC, who request supplementary information for the doctoral program which is not covered by the external accreditation;

- review panel selected with some members being nominated by the external accreditation board and others by the GPEC;

- $\quad$ site visit conducted by combined review panel;

- independent but coordinated reports produced by the two sets of reviewers; 
- decisions made independently by the GPEC (for academic program review) and the external accreditation board (for the accreditation review).

\section{Discussion and recommendations}

Feedback on the pilot project was gathered from three main sources: 1) the program coordinators; 2) the external reviewers; and 3) the Graduate Program Evaluation Committee members. In this section, we will discuss some of the key points raised by each of these groups, and then we will present fourteen recommendations that we have developed based on our experience in aligning professional accreditation and academic program reviews as part of this pilot project. These recommendations may be helpful to other colleagues working in quality assurance in higher education settings in Canada or elsewhere in the world, who are seeking to carry out aligned reviews.

\section{Feedback on the pilot project}

The program coordinators of the Occupational Therapy program and of the Social Work program were both interviewed separately by the Vice-Dean, who oversees the graduate quality assurance office. In both cases, the 20-minute interview took place approximately one week after the site visit for the aligned review.

Both of the program coordinators expressed appreciation for the opportunity to produce a single self-study document instead of two separate documents. In their opinion, the content needed for both types of review was very similar, but they both commented that it would have been a lot of extra work to reformat and reformulate this content into two different templates. By producing just one self-study, the program coordinators felt they had saved a significant amount of time. Similarly, the program coordinators were grateful for the opportunity to organize a single site visit. Both commented that it can be challenging to round up a representative cross-section of stakeholders such as faculty, students, alumni, staff, special services personnel (e.g. librarians, co-op coordinators), and community members (e.g. internship employers). One of the coordinators commented on the risk of "participation fatigue," noting that she did not want to overstep the bounds of the goodwill of these stakeholders by asking them to participate in numerous reviews. By aligning the reviews, a single site visit could be organized, and this reduced the time investment required not only by the organizers in the academic unit, but also by the stakeholders themselves (in terms of number of person hours). In terms of financial costs, both coordinators commented favourably on the savings that were made possible by having a single streamlined review panel as this allowed the academic unit to reduce the costs associated with travel and honoraria. The main piece of advice shared by both program coordinators was to allow for a period of socializing the idea of the aligned review with both the professional association and the institutional committee as both may be skeptical at first and have a number of questions. To facilitate communications in this regard, both program coordinators also recommended sharing the general requirements of both review processes (e.g. the standards or criteria to be evaluated) with both groups, as well as identifying a single person as a point of contact for both groups to help build up a trust relationship.

When gathering feedback from the reviewers, the Vice-Dean interviewed the entire fourmember review panel for the Social Work program as a group at the very end of the site visit (25 minutes). For the Occupational Therapy program, the Vice-Dean interviewed one reviewer who was acting for the accreditation body and one reviewer who was acting for the Graduate Program 
Evaluation Committee, and these 20-minute interviews were conducted independently via telephone approximately one month after the site visit. In all cases, it was clear that the reviewers appreciated the opportunity to participate in a process that allowed them to gain a more holistic view of the program. However, it was also clear that they viewed themselves as being part of "separate but coordinated" teams, and that they valued this arrangement. It was important to them that their own particular role was clear, and this included knowing what "checklist" they needed to verify, as well as knowing the intended recipients of their respective reports. While the reviewers were happy to receive the same single self-study document, they expressed a preference for preparing separate reports. While all the reviewers felt respected by their teammates, one reviewer did comment that some of the stakeholders seemed to give priority to the professional accreditation components of the review, giving the perception that this review was more important than the academic program review. While it is not possible to generalize from this limited experience, it nevertheless points to the importance of setting appropriate expectations for stakeholders. All reviewers commented that it was important to keep the overall size of the review panel to a reasonable size to facilitate teamwork, and four was generally seen as the upper limit for an effective team. Similarly, all reviewers were in agreement that a threeday visit seemed to be an optimal length for an aligned review because it allowed all the requirements for both review processes to be investigated in sufficient depth.

Finally, members of the Graduate Program Evaluation Committee (GPEC) were asked by the Vice-Dean (who chairs the committee) to provide feedback on the two aligned reviews during one of their regular committee meetings. The GPEC members felt that the pilot project had been successful overall, but they nonetheless felt that it would be important to take into account certain factors moving forward. Firstly, the committee members felt strongly that it was important to assess each request for an aligned review on a case-by-case basis. On the one hand, this was owing to the wide variety of disciplinary and association norms that exist, some of which may align more closely with the institutional quality assurance requirements than others. On the other hand, it was noted that while the two programs participating in the pilot study had no history of problems, this is not always the case. For instance, if a program has previously been granted a conditional approval, it may be wise not to conflate two different sets of requirements into a single self-study or review. Rather, the program might be better served by addressing the issues that have been flagged as part of a specific review process and getting itself on a solid footing. Another observation made by the GPEC members was that it had been extremely helpful during their discussions to have input from a committee member who had previous direct experience of professional accreditation reviews. Finally, the GPEC members appreciated receiving separate reports from the two sets of reviewers. Having the two reports allowed them to gain a more holistic view of the program, but they were able to ensure that all the necessary questions were addressed in the report that corresponded to their own review process requirements.

Table II provides a summary of the positive feedback and concerns that were raised. The points are marked with OT or SW depending on whether they were raised in connection with the aligned review of the Occupational Therapy program or the Social Work program.

\begin{tabular}{|l|ll|}
\hline \multicolumn{1}{|c|}{ Positive feedback } & \multicolumn{1}{c|}{ Concerns } \\
\hline - $\begin{array}{l}\text { producing a single self-study saved time and } \\
\text { effort (OT, SW) }\end{array}$ & $\bullet \begin{array}{l}\text { providing adequate time to socialized the idea } \\
\text { of an aligned review is essential (OT, SW) } \\
\text { conducting a single site visit saved time and } \\
\text { effort (OT, SW) }\end{array}$ & $\bullet \begin{array}{l}\text { nominating one liaison person from the } \\
\text { program will support the establishment of trust }\end{array}$ \\
\hline
\end{tabular}


- conducting a single site visit reduced the risk of participation fatigue among stakeholders (SW)

- aligning reviews reduced financial costs (OT, SW)

- $\quad$ aligning reviews allowed for a more holistic program assessment (OT, SW)

- $\quad$ organizing a three-day visit gave adequate time for an appropriate review (OT, SW)

- $\quad$ selecting a total of four members for the combined panel proved appropriate (OT, SW)

- $\quad$ providing separate but coordinated reviews is most helpful (OT, SW)

- approving aligned reviews on a case-by-case basis is important (OT, SW)

Table II. Summary of positive feedback and concerns raised during the evaluation of the pilot project to align academic program reviews and accreditation reviews for the graduate programs in Occupational Therapy (OT) and Social Work (SW).

\section{Recommendations}

Based on our experience aligning the professional accreditation and academic program reviews for these two graduate programs, and on the feedback provided by the program coordinators, the reviewers, and the members of the Graduate Program Evaluation Committee, we have compiled a list of fourteen recommendations that can help to set the scene for a successful aligned review are presented.

\section{Approve aligned reviews on a case-by-case basis}

In the case of both programs participating in the pilot study, there was a good alignment between the expectations of the accreditation body and those of the GPEC. However, before formally agreeing to proceed with an aligned review, it would be prudent to begin by examining the professional accreditation standards and guidelines, and then conduct a gap analysis of the selfstudy to determine whether additional material must be supplied. At the University of Ottawa, the GPEC has formally reserved the right to evaluate requests for aligned reviews on a case-bycase basis.

\section{Ensure that the two elements of the aligned review are seen as being equally important}

For an aligned review to succeed, it is very important that all stakeholders recognize that the two elements of the review - the program review and the accreditation review - are equally important. That is to say, the relationship between the two is non-hierarchical. This message must be clearly conveyed to all stakeholders, including faculty members, staff, students, alumni, as well as members of the program review committee and the accrediting body. If any members of the review team are internal to the university (as may be the case for a cyclical review), these members are encouraged to allow the external reviewers to ask their questions first, and to follow up with complementary questions where necessary.

\section{Do not pursue an aligned review with a program that has known or suspected difficulties}

Sometimes it is known or suspected in the lead-up to a review that a given program is struggling with one or more issues. An example might be a program that received a conditional status 
during the preceding review. In such a case, an aligned review might be perceived as an added pressure or a significant risk.

\section{Socialize the possibility early and often with both the program review committee and the accrediting body}

The notion of conducting aligned reviews is still relatively new, and it may be met with skepticism on both sides as each group will be keen to ensure that their own values and objectives are respected. Be sure to leave lots of time for discussion, listen to and address concerns coming from the other group, and recognize that it may take time to obtain buy-in and to fully understand the processes, practices and expectations of both sides. Also, remember that some committees may not meet as frequently as others, so be sure to start early.

\section{Ensure that at least one member of the program review committee has accreditation experience}

In the case of this pilot project, it was extremely helpful that several members of the GPEC taught in programs that were subject to professional accreditation and had participated in accreditation reviews as faculty members or program directors. These colleagues were instrumental in helping other committee members who had no prior experience of professional accreditation to understand the issues and to buy in to the possibility of an aligned review.

\section{Nominate a liaison person to communicate with both the program review committee and the accrediting body}

To facilitate communication and help to establish trust, it is helpful to have a single person who acts as a liaison between the program review committee and the accreditation committee. This could be the director of the program under review, the director of the academic unit that delivers the program, or an accreditation coordinator working in the Faculty, for example.

\section{Share documents and information with both the program review committee and the accrediting body}

To promote transparency and to gain buy-in from both sides for an aligned review, share documents and information, such as templates, guidelines, standards, and other materials normally provided to a program undergoing review with both the program review committee and the accrediting body. This will allow both groups to better understand where there is overlap and where there are differences between the two review processes.

\section{Ensure that the overall composition of the review panel meets the needs of both groups}

It is not necessary for each and every reviewer to fulfill the desired profile of both groups, but the overall composition of the committee should be such that the needs of both groups will be adequately addressed. A review panel of 3 to 4 members would seem to be ideal. If the group is much larger, then each meeting with a stakeholder group is likely to become longer as all reviewers attempt to participate. In a case where each group needs to ensure a minimum number of reviewers, it would be better to collaborate and mutually agree on the selection of a group of 3 or 4 reviewers, rather than sending a full complement from each group and ending up with an unwieldy review panel. The cyclical review process may allow for more flexibility in this regard, but the important thing is to adopt a collaborative approach to ensure that the needs of both groups are met. 
9. Identify the roles and responsibilities of each member of the review panel

Ensure that each member of the review panel receives clear instructions about their respective role and responsibilities as part of the review. For example, if there are multiple programs involved, be sure that reviewers know which program(s) they are responsible for reviewing. Similarly, if there is a particular template to be followed, or a particular set of questions to be explored with stakeholders, make certain that this is clear.

\section{Ensure that an appropriate amount of time is allocated for the site visit}

In the case of cyclical reviews, the site visit normally takes place over two full days. However, to ensure the smooth functioning of an aligned review, it may be necessary to allocate more time to ensure that the review team is able to fully explore issues that are of interest to both the program review committee and the accrediting body. In the case of the two aligned reviews that were part of the pilot project, the site visits lasted three days, rather than two. In addition, as part of the itinerary, it may be relevant to build in time for the internal reviewer (e.g. for a cyclical review) to meet with key individuals separately to focus on internal business as needed. For instance, there may be items that are not relevant to an accrediting body but that would be important to highlight as part of an internal review.

\section{Designate a room for the reviewers' exclusive use during the site visit}

It may be helpful to provide a home base for the reviewers during their visit. This designated room could contain copies of all documents that are relevant to both reviews so that no time is wasted looking for documents during the visit. When there are two review teams, having a dedicated room becomes more important in the event that one group needs to meet privately. As a courtesy, this room could also contain waters, snacks, etc. It becomes a place for the reviewers to retreat to when they need to discuss and work either together or separately.

\section{Kick off the site visit with a meeting between all the reviewers}

At the very beginning of the site visit, allow the review panel to meet as a group without any other people present for the first 30 minutes or so. This will give the reviewers a chance to meet, introduce themselves, and clarify their respective roles and responsibilities with regard to one another. Such a meeting will help to set the right tone that they are working in concert on the aligned review, rather than simply in parallel.

\section{Request separate reviewers' reports, but read them "together"}

Given that the members of the aligned review team have slightly different mandates, it may be useful to request that separate reports be produced for the program review committee and the accrediting body. However, this does not mean that the reviewers cannot collaborate or coordinate their reports because, ideally, both reports will be made available to the program review committee and the accrediting body, who can then read them together to gain a fuller overall picture of the program.

\section{Share responses and follow-up reports}

If the academic unit is required to prepare a response to the reviewers' reports, or to produce a follow-up report in the period following the aligned review, these documents should also be shared with both the program review committee and the accrediting body. By sharing these 
materials with both groups, the academic unit can hopefully reduce their overall reporting requirements. In addition, the continued collaboration between the program review committee and the accrediting body will hopefully pave the way for an even smoother aligned review the next time around.

\section{Concluding remarks}

In an effort to contribute to a deeper understanding of, and engender wider discussion about the potential benefits and limitations of aligning professional accreditation and academic program reviews, the graduate quality assurance team at the University of Ottawa undertook a one-year pilot project in which the professional accreditation and academic program reviews for two graduate programs were aligned. The positive and negative feedback from a variety of stakeholders who participated in the pilot project have been summarized in Table 2. To add practical value to this policy paper, we compiled a list of fourteen recommendations that may be useful for designing and carrying out aligned reviews in similar institutional contexts in the future. In this concluding section, we will provide an overall summary of the potential benefits and limitations of aligning reviews.

Our experience with this institutional case study suggests that there are three main benefits to the program review alignment process, and four potential disadvantages, as detailed below.

Benefit 1. Cost efficiency and reduced time demands. One common motivation for seeking to align a professional accreditation with an academic program review is that an aligned review can significantly reduce the burden on programs with regard to the time and effort invested by faculty and staff and other stakeholders. Moreover, with regard to finances, costs such as honoraria and travel expenses for the reviewers can also be reduced.

Benefit 2. Free up more time for academic faculty to pursue educational tasks. In addition to offering a resource-efficient option, aligned reviews present other potential benefits as well. For example, when members of an academic unit are spending much of their time on the actual tasks of preparing self-studies and writing various associated reports, they may not have adequate time to fully reflect on or implement the bigger picture issues, such as enhancing the program or aligning the program objectives with the strategic goals of the institution. The literature contains numerous accounts of faculty members who have expressed the opinion that the minutiae of quality assurance exercises divert their attention from what they see as more important aspects of their jobs (Cardoso et al., 2013: 98; Manatos et al., 2015: 246). These concerns were echoed by academic units at the University of Ottawa. If faculty members are free to dedicate more time to the true spirit of holistic self-assessment and continuous quality improvement, and spend less time on the associated reporting tasks, then these faculty members are likely to be more willing to participate and be more fully engaged in the process, which ultimately lead to enhanced programs.

Benefit 3. Reviewer education on different review requirements. The reviewers who participate in aligned reviews may also benefit from the experience because it allows them to gain a more holistic view of the program under review, and to appreciate its different facets and elements more fully. This well-rounded review process, which produces coordinated feedback for the academic unit, will hopefully emphasize the links between the program and the profession and result in more robust and meaningful recommendations for program enhancement. 
Disadvantage 1. When outcomes of previous reviews vary, reviews may be difficult to align. While there are potential benefits to be gained by aligning accreditation reviews and academic program reviews, there could be situations where an aligned review is not feasible or desirable. For example, as mentioned in recommendation 3 above, if a program received a conditional status in the preceding review, it may not be desirable to conduct an aligned review until it is clear that any serious issues that were flagged have been resolved.

Disadvantage 2. When length of different review cycles vary, reviews may be challenging to align. The length of the review cycle may be another factor that influences the decision as to whether or not to align reviews. If the length of the review cycle is considerably different (e.g. five years for a professional accreditation and eight years for an academic program review), it may not be convenient to align the reviews. Or in other cases, it may be of interest to try to align and segregate the reviews in an alternating pattern (e.g. in 2020 an aligned review, in 2027 segregated reviews, in 2034 an aligned review, and so on).

Disadvantage 3. If required qualifications of reviewers for different types of review vary, reviews cannot be easily aligned. In recommendation number 8 above, it was noted that to ensure the success of an aligned review, it is necessary to make certain that the overall composition of the review panel meets the needs of both groups. However, if the required qualifications for the two groups of reviewers are too different (e.g. professional qualifications vs academic qualifications), and a single combined panel would be too large and unwieldy, this could lead to a decision to opt for segregated reviews. Similarly, if the evaluation criteria set out by the accrediting body and the program review committee show little evidence of overlap, there may be little point in attempting to produce a single self-study with a view to undergoing an aligned review.

Disadvantage 4. When reviewers for the different reviews vary in their program assessments, conflicts may be difficult to resolve. Finally, an area worthy of further consideration is the question of what to do if the two sets of reviewers arrive at different or conflicting findings. Given that the two groups are approaching the program evaluation through a different lens, it is possible that they may emphasize different elements or place a different level of importance on a given element during the review. It is important to remember that an aligned review is not a single review, but rather a coordinated review that allows for sensible alignment of an accreditation review with an academic program review. As such, the two sets of reviewers should be free to explore the program from different angles, and to present their findings in their independent reports. While the accrediting body and the program review committee are encouraged to read the two reports together, their members will then need to use their best judgement with regard to how to interpret, weigh and apply the findings of the two panels in order to best meet the objectives of their respective processes. As more aligned reviews take place, it is hoped that best practices will emerge in this regard.

To end, our goal with the pilot project was to learn more about the potential advantages and drawbacks of aligning accreditation reviews and academic program reviews. We hope that the summary and recommendations provided in this policy paper will serve to advance the discussion about the alignment of academic program reviews and professional accreditation reviews.

\section{References}


Brown, R. (2004), Quality Assurance in Higher Education: The UK experience since 1992, Routledge, London.

Canadian Association of Occupational Therapists (CAOT). (2011), CAOT Academic Accreditation Standards and Self-Study Guide, http://www.caot.ca/acc/CAOT\%20Accreditation\%20Self-Study\%202011\%20(rev.\%202014).pdf

Canadian Association for Social Work Education (CASWE). (2014), Standards for Accreditation, http://caswe-acfts.ca/wp-content/uploads/2013/03/CASWE-ACFTS-Standards11-2014.pdf

Cardoso, S., Rosa, M. J., and Stensaker, B. (2016), "Why is quality in higher education not achieved? The view of academics", Assessment and Evaluation in Higher Education, Vol. 41 No. 6, pp. 950-965.

Goff, L. (2013), "Quality Assurance Requirements in Ontario Universities: How did we get here?”, in Kompf, M. and Denicolo, P. M. (Eds.), Critical Issues in Higher Education, Sense Publications, Rotterdam, pp. 97-114.

Guitard, P., and Savard, J. (2016), "Accreditation and Institutional Quality Assurance Process: How to Kill Two Birds with One Stone", Newsletter of the Association of Canadian Occupational Therapy University Programs, Fall 2016, pp.5-6. http://www.acotupacpue.ca/Newsletters/Fall2016/files/assets/basic-html/page-5.html

Jones, J. and Darshi de Saram, D. (2005), “Academic Staff Views of Quality Systems for Teaching and Learning: a Hong Kong case study”, Quality in Higher Education, Vol. 11 No. 1, pp. 47-58.

Liu, Qin. (2015), “The Quality Assurance System for Ontario Postsecondary Education: 2010 2014", Higher Education Evaluation and Development, Vol. 9 No. 2, pp. 55-79.

Macmillan English Dictionary:

http://www.macmillandictionary.com/dictionary/american/alignment

Manatos, M. J., Rosa, M. J. and Sarrico, C.S. (2015), "The importance and degree of implementation of the European standards and guidelines for internal quality assurance in universities: the views of Portuguese academics", Tertiary Education and Management, Vol. 21 No. 3, pp. 245-261.

Materu, P. (2007), "Higher Education Quality Assurance in Sub-Saharan Africa: Status, Challenges, Opportunities, and Promising Practices", World Bank Working Paper No. 124. The World Bank, Washington, D.C. https://openknowledge.worldbank.org/handle/10986/6757

Mora, J.-G. (2004), “A Decade of Quality Assurance in Spanish Universities”, in Schwarz, S. and Westerheijden, D. F. (Eds.), Accreditation and Evaluation in the European Higher Education Area, Kluwer Academic Publishers, Dordrecht, pp. 421-443. 
Ontario Universities Council on Quality Assurance. (2010), Quality Assurance Framework, http://oucqa.ca/resources-publications/quality-assurance-framework/

Shah, M., Nair, S. and Wilson, M. (2011), "Quality Assurance in Australian Higher Education: Historical and Future Development”, Asia Pacific Education Review, Vol. 12 No. 3, pp. 475-483.

Strydom, J. F., Zulu, N. and Murray, L. (2004), “Quality, Culture and Change”, Quality in Higher Education, Vol. 10 No. 3, pp. 207-217.

Subramony, R., Wallace, S. and Zack, C. (2015). "Toward an Aligned Accreditation and Program Review Process: Institutional Case Study", Higher Learning Commission Annual Conference: 2015 Collection of Papers.

http://cop.hlcommission.org/Planning/subramony2015.html

Tam, M. (1999), "Quality Assurance Policies in Higher Education in Hong Kong”, Journal of Higher Education Policy and Management, Vol. 12 No. 2, pp. 215-226.

University of Ottawa. (2011), Institutional Quality Assurance Process (IQAP), https://www.uottawa.ca/graduate-studies/sites/www.uottawa.ca.graduatestudies/files/uo_iqapgraduatestudies_final_version_june_27_2011.pdf

Vlăsceanu, L., Grünberg, L. and Pârlea, D. (2007), Quality Assurance and Accreditation: A Glossary of Basic Terms and Definitions, UNESCO, Bucharest. http://oucqa.ca/wpcontent/uploads/2013/04/UNESCO-Glossary-of-Basic-Terms-and-Definitions-2007.pdf

Weinrib, J. and Jones, G.A. (2014), "Largely a Matter of Degrees: Quality Assurance and Canadian Universities", Policy and Society, Vol. 33, No. 3, pp. 225-236. 